\title{
Perfil de los usuarios activos y finales de clubes deportivos de Bogotá D.C.
}

\section{PROFIL OF ACTIUE AWI FIWAL USERS OF SPORT HLUBS II BOAOTA}

FECHA DE RECEPCIÓN: 17 de febrero de 2010 FECHA DE APROBACIÓN: 29 de abril de 2010 Pp. 134-153

\section{Billy Crissien * Omar Fernando Cortés ** Marithza Sandoval ***}

* Magister en Gestión de Organizaciones e Instalaciones Deportivas-Universidad Politécnica de Madrid; Administrador de empresas-Universidad EAN; Profesor asociado de la universidad EAN.

** Psicólogo especializado en Psicología del Consumidor; docente investigador de la Universidad EAN, Investigador becario de COLCIENCIAS en el Doctorado de Psicología de la Universidad del Norte de Colombia.

\footnotetext{
*** Magister en Psicología; Especialista en Psiología del Consumidor, Directora de postgrado de Psicología del Consumidor Fundación Universitaria Konrad Lorenz, Coordinadora Clúster de Investigaciones.
} 


\section{RESUMEN}

$E^{s t}$ te artículo es el resultado de la investigación que tuvo por objeto establecer las características del comportamiento de los consumidores de clubes deportivos de la ciudad de Bogotá, determinando sus características demográficas y psicográficas. Se pretendió caracterizar y clasificar los conglomerados de usuarios en términos del nivel socioeconómico, nivel educativo, estado civil y aspectos ocupacionales. Otro objetivo que se tuvo en cuenta fue el de identificar el patrón de consumo de servicios ofertados por los clubes deportivos, los factores motivacionales asociados con la lealtad de los usuarios hacia los clubes en las diferentes disciplinas deportivas y analizar el caso particular de los hinchas de equipos profesionales. Para esto, se desarrolló una investigación descriptiva con encuestas a 336 usuarios activos y finales de clubes deportivos en la ciudad de Bogotá. Los resultados muestran un perfil diferencial para jugadores y espectadores a nivel de estilo de vida, hábitos saludables y patrón de interacción con los eventos deportivos. Los hinchas de los equipos profesionales de fútbol poseen un perfil similar al de los usuarios finales de los clubes de otras disciplinas, pero evidencian un nivel de involucramiento mucho más alto.

\section{Palabras claves}

Clubes deportivos,

Usuarios activos,

Usuarios finales,

Comportamiento del consumidor,

Perfil psicográfico,

Perfil demográfico,

Hinchas de fútbol.

\section{ABSTRACT}

$\mathrm{T}$

his This article is the result of a research made to establish behavioral features of

sport clubs consumers in the city of Bogota, specifying demographic and psychographic features. It characterize and classify the groups of users in terms of socioeconomic level, educational level, marital status and job issues. Another important aim is to identify the consuming pattern of service offers at sport clubs, the motivational factors related with the loyalty of users towards clubs offering various sport disciplines, analyzing the particular case of professional teams fans. For this reason, a descriptive research was made applying 336 interviews to active and final users of sport clubs in the city of Bogota. The results show a differential profile for players and fans regarding lifestyle, healthy habits and interacting patterns with sport events. The fans of football professional teams have a profile similar to the final users of the clubs of any other disciplines, but giving evidence of a higher involvement level.

\section{RÉSUMÉ}

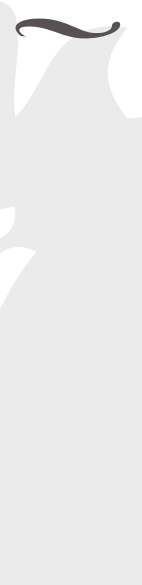

\section{Key Words}

Sport Clubs

Active Users

Final Users

Consuming Behaviour

Psychographic Profile

Demographic Profile

Football Fans

Cet article est le résultat d'une recherche ayant pour objet d'établir les caractéristiques

du comportement des consommateurs des clubs sportifs de la ville de Bogotá et ce du point de vue de leurs caractéristiques démographiques et psycho graphiques. Il s'agit de caractériser et de classifier les utilisateurs en termes de catégorie socioéconomique, de niveau de scolarisation, d'état civil, de situation professionnelle. Un autre objectif pris en compte fut d'identifier le modèle de consommation des services offerts par les clubs sportifs, les facteurs motivationnels associés à la fidélité des utilisateurs aux clubs de différentes disciplines sportives et d'analyser le cas particulier des supporteurs des équipes professionnelles. Une investigation descriptive de 336 adhérents actifs aux clubs sportifs de la ville de Bogotá a été nécessaire à cette fin. Les résultats montrent un profil différent entre joueurs et spectateurs au niveau du style de vie, des comportements salutaires et des types d'interactions aux évènements sportifs. Les supporteurs des équipes professionnelles de football ont un profil similaire à celui des utilisateurs finaux de clubs d'autres disciplines mais montrent un niveau d'implication beaucoup plus grand. 


\section{Introducción}

$\mathrm{H}$ asta el año 2007, según datos del IDRD, se contaba con 1.120 clubes deportivos debidamente registrados. Esta cifra no incluye aquellos clubes informales, los cuales abundan en las diferentes zonas de la capital, por lo que se estima que este segmento del sector deportivo, puede ser aún mayor. En este estudio se encontró que los clubes formales e informales de Bogotá, poseen características administrativas y financieras muy sencillas, asociadas frecuentemente con PYMES de otros sectores. Usualmente son unipersonales o familiares, con una gestión reactiva y con ausencia de formación para realizar las labores características de su misión. Existen algunos clubes grandes, especialmente en el caso del fútbol, pero se evidencia un desconocimiento general en el segmento respecto de quién es su consumidor, cómo abordarlo proactivamente y generar fidelización.

Con el fin de profundizar en el conocimiento de este segmento, es necesario abordar la visión de la demanda de servicios ofertados por los clubes deportivos. Para esto, se requiere caracterizar los consumidores de los clubes, en términos de los aspectos psicográficos y demográficos, así como las expectativas relacionadas con el deporte en general. Los datos derivados de esta investigación permiten ofrecer información valiosa a los clubes deportivos para fundamentar los planes estratégicos de la organización y fortalecer el sector a través de las iniciativas privadas.

\section{El marketing deportivo y el comportamiento de los consumidores}

A través del tiempo, el deporte ha pasado de ser una simple actividad física que se realiza en contextos sociales, a convertirse en un proceso de intercambio económico donde influyen variables complejas de diversas índoles. Estas variables son de naturaleza social, económica, cultural y psicológica y sus ámbitos de impacto también se encuentran en estas esferas.

Pedroza y Salvador (2003) indican que la economía del deporte constituye un área relativamente nueva de investigación. El pensar el deporte en términos económicos ha contribuido a generar nuevos y productivos mercados, a generar diferentes oportunidades de empleo y a promover un estilo diferente de toma de decisiones en lo referente a la gestión deportiva. Estos autores afirman que a través del tiempo, el deporte moderno (sustentado tradicionalmente a través de organizaciones, competiciones, selecciones, mediciones, afiliaciones, etc.) se ha ido articulando en torno a dos tendencias distintas: el Business Sport, basado en las reglas de mercado, y el Deporte para todos, forma de socialización sin vínculos organizativos ni competitivos, en la que las actividades deportivas (individuales y colectivas) se relacionan, a menudo, con el turismo o la salvaguardia de la propia salud y del bienestar social (pg. 3). Ambas vertientes poseen aproximaciones y métodos diferentes, conformándose los dos tipos de deporte: el profesional y el amateur. En el primero, los protagonistas son practicantes o deportistas, mientras que en el segundo, las personas emplean su tiempo libre para practicar o ser espectadores. La cantidad de individuos que se dedican a cualquiera de las modalidades es cada vez más creciente y el tamaño económico del sector deportivo aumenta gradualmente, merced a los bienes asociados con las prácticas deportivas, la publicidad, el mercadeo, los espectáculos y en general al desarrollo del mercado del ocio (Pedroza y Salvador, 2003). 
Como un ejemplo, se observa que el mercado global de calzado deportivo asciende a 33,000 millones de dólares y Estados Unidos representa el $50 \%$ del total de ese mercado. Solamente en el 2008 se vendieron 413 millones de pares de tenis en ese país. Las marcas más importantes del mundo en el 2009 fueron Nike, con una participación del 33\% del mercado global; Adidas y Reebook, que ahora forman parte de una misma empresa y que ostentan, en conjunto, el $25 \%$ del mercado mundial; Puma y New Balance quienes tienen el $7 \%$ del mercado cada una (extraído en noviembre del 2009 del sitio http://www. latinamerican-markets.com).

El crecimiento del sector deportivo en el mundo, ha conllevado el desarrollo del denominado marketing deportivo. Fransi (2004) lo define como el conjunto de actividades destinadas a satisfacer las necesidades de los consumidores del producto deportivo a través del intercambio. Se definen dos ámbitos de aplicación del marketing deportivo, aquel relacionado con los consumidores finales y el relacionado con la gestión comercial a través del patrocinio.

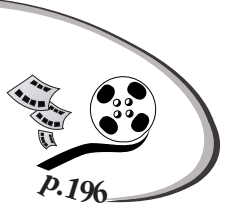

Como lo menciona Fransi (2004) en el caso español, el aumento en el tiempo libre y los estilos de vida de las personas, han convertido al deporte en un espectáculo que ocupa un lugar muy importante en las vidas

de las personas. Esta situación obliga al gerente deportivo a implementar estrategias de marketing para mantener sus consumidores actuales, capturar nuevos consumidores y cultivar los consumidores del futuro. Este es el sentido verdadero del marketing deportivo y es la razón por la cual este ha tomado un lugar importante en la formación administrativa de postgrado, así como en el diseño de las estructuras organizacionales de las empresas del sector.

Así por ejemplo, apenas en el 2007, Jose Ramil, Vicepresidente de Master-Card, señalaba que era muy difícil determinar cuánto reservan las empresas para financiar la Copa América y agregaba, que respaldar la Copa América era una vitrina comercial que permitía comunicar al público las novedades de Master-Card, Cirrus y Maestro. Por su parte, Enrique Arribas, Gerente de Patrocinios de Telefónica Movistar, sólo indicó que del presupuesto anual de 2007, la compañía destinó cerca de 20\% para apadrinar la Copa America. Así mismo, Carlos Martínez, Gerente de Mercadeo Deportivo de Empresas Polar, tampoco precisó cuánto dirigió la compañía al respaldo de actividades deportivas, pero sugirió que fue una cifra sustancial (Alfonzo, 2007).

Desde el punto de vista académico, diversas disciplinas han comenzado a desarrollar intereses conceptuales y líneas de investigación relacionadas con el marketing dentro del sector deportivo. Tal es el caso del planteamiento de modelos de medición del tamaño e impacto económico del sector (Pedroza y Salvador, 2003) y el fortalecimiento del cuerpo de investigación relacionado con el comportamiento del consumidor del deporte. Smith y Stewart (2009) indican que aunque el negocio del deporte es complejo,

debido a que muchas veces los productos son de naturaleza idiosincrática, no se puede ignorar el fuerte componente cultural que posee y las fuertes experiencias emocionales que derivan sus

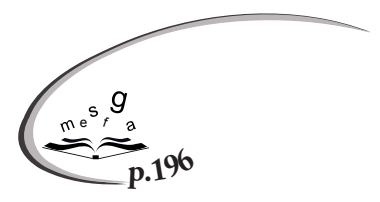
consumidores. Las grandes sumas de dinero asociadas con este sector comercial, han hecho necesarias las investigaciones respecto de las características de la oferta y de la demanda.

Este último aspecto, principalmente se ha desarrollado dentro del campo de la psicología del consumidor. Para esta área de conocimiento, el comportamiento de las personas en escenarios de compra y consumo es muy difícil de abordar en virtud de la gran cantidad de variables que interactúan para determinarlo. Siendo un objeto de estudio multicausado y complejo, implica diversos problemas prácticos al momento de definir las estrategias más efectivas para su abordaje.

Una alternativa consiste en analizar los comportamientos de compra y consumo a partir de variables que se clasifican en niveles. Esta puede ser una alternativa útil para organizar el mapa de influencias y plantearse hipótesis que deben ser corroboradas a través de la investigación. En un nivel de macroambiente se incluyen aquellas variables que afectan grandes grupos poblacionales, generando cambios globales en las tendencias de consumo en toda una sociedad e inclusive en el mundo entero. En el nivel de microambiente se consideran las influencias provenientes de la familia, los grupos de pertenencia, la situación de compra y comunicación. Su acción es mucho más limitada a grupos particulares de individuos. Finalmente, en el nivel individual se clasifican las influencias de los procesos psicológicos del consumidor sobre sus comportamientos de compra y consumo. Estos procesos incluyen la memoria, aprendizaje, motivación, actitudes y procesos de 
decisión de las personas, determinando diferencias individuales en casos particulares (Sandoval, 1994).

Bajo una perspectiva de niveles de análisis, el estudio del comportamiento de los consumidores del sector deportivo requiere un enfoque interdisciplinario, donde las ciencias sociales, las ciencias económicas y administrativas, y aún las ciencias biológicas aporten modelos conceptuales y datos de investigación valiosos para la comprensión y predicción del consumo deportivo. Esta tarea es relativamente joven, si se considera la larga trayectoria de análisis del consumidor en otros sectores económicos (por ejemplo en el caso del consumo masivo).

Al revisar la literatura de investigación disponible en el área del consumidor del sector deportivo, uno de los tópicos de mayor interés ha sido el estudio de las características y determinantes del fan de clubes en diferentes deportes, pero principalmente en el fútbol.

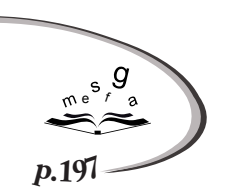

Funk, Ridinger y Moorman (2003) indican que los fans como consumidores han creado una gran cantidad de retos y oportunidades que requieren un análisis profundo de sus motivaciones, preferencias y actitudes. Los autores sugieren que se ha enfatizado en dos grandes dimensiones. La dimensión externa, referida a las instalaciones, tipo de competencias, contexto geográfico, entre otros. La otra dimensión que se ha analizado se relaciona con el perfil psicológico de los fans. No obstante, en comparación con otros campos de investigación, existen pocos estudios respecto al perfil psicológico del espectador de deportes.

Uno de los temas de interés ha sido la investigación de las actitudes del consumidor de clubes deportivos. Por ejemplo, Funk y James (2004) construyeron un modelo que plantea una mejor medida de la formación de actitudes frente a los equipos; este se denomina Red de Actitudes del Hincha (FAN) y se ha aplicado a investigar como las personas valoran las acciones de los clubes y su fidelidad con los mismos. Así mismo, Funk y Pritchard (2006) demostraron que los fans más comprometidos afectivamente con su equipo atienden más a las noticias positivas, mientras que los fans menos comprometidos recuerdan más las noticias negativas. Los estudios acerca de las actitudes podrán permitir en el futuro una diferenciación de los consumidores respecto de su unión afectiva con los equipos y predecir que tanto podrían ser susceptibles de nuevos productos $\mathrm{y}$ campañas de comunicación.

Respecto de la manera como se desarrollan estas actitudes y el involucramiento de los hinchas con los clubes deportivos, Fink (2002) plantea la existencia de diferentes mecanismos de aprendizaje, pero se muestra a favor de la hipótesis de que la identificación con un nuevo club se realiza principalmente a través de aprendizaje vicario. En otras palabras, los niños y las generaciones más jóvenes aprenden de los mayores la pertenencia a un club y a ser fanáticos, con un patrón de lealtad característico. Esto podría explicar por quéla afición se genera a través de familias y grupos, convirtiéndose en una tendencia social. Como un ejemplo, Lock, Darcy y Taylor (2009) analizaron la dinámica de formación de identidad en miembros de los clubes a partir del cambio de la Liga Nacional de Soccer a la Liga A, a partir del año 2003. Los resultados mostraron que este proceso de identidad con el nuevo club se comienza a desarrollar después del primer año y que las variables edad e ingreso, son fuertes predictores del desarrollo de dicha identidad. Esto significa que a mayor edad, menor es la probabilidad de identificarse con un nuevo club, dado que han pasado ya las etapas tempranas de socialización, mientras que en las personas jóvenes existe una mayor plasticidad en el comportamiento y por tanto, es más factible el desarrollo de vínculos emocionales permanentes entre los hinchas y los equipos de diferentes disciplinas deportivas.

Otro punto interesante que se ha encontrado, es que existe un perfil psicográfico diferencial del consumidor practicante del deporte y miembro de un club, en comparación con aquel consumidor que juega del papel de espectador de los eventos deportivos. Wicker, Breuer y Pawlowski (2009) investigaron el gasto que realizaban 10.013 miembros de clubes deportivos informales. Se investigaron 21 deportes y se encontró que en Alemania, estos consumidores activos gastan un promedio de 1610 euros en el deporte de su elección. Se observaron importantes diferencias entre el gasto dependiendo del tipo de deporte. Los principales predictores del gasto, en un análisis de regresión, fueron 
el ingreso personal, el desempeño deportivo y el tiempo semanal dedicado al deporte. Estos datos demuestran que los usuarios activos de los clubes deportivos invierten más dinero dependiendo del grado de compromiso o involucramiento con el deporte que practican, pero que su ingreso limita esta inversión. En otras palabras, a mayor involucramiento con la actividad deportiva mayor gasto en eventos, productos y rutinas asociadas con el deporte.

El deporte y la actividad física en Colombia muestran cifras preocupantes. En particular, Bogotá muestra estadísticas preocupantes respecto de la actividad física (Duperly et al., 2005). Hasta el año 2003, solamente el $37 \%$ de las personas practicaban regularmente actividades físicas y este porcentaje se encontraba principalmente en individuos menores de 30 años. En un estudio más reciente de la Fundación FES Social (2009), en Bogotá, el 55.3\% de los adultos no realiza ninguna actividad física y el $20.1 \%$ de las muertes en la ciudad son causadas por enfermedades que pueden ser atribuidas a la inactividad física. Como una manera de contrarrestar esta situación, la Alcaldía Mayor de Bogotá ha lanzado la Política Pública de Deporte, Recreación y Actividad Física para Bogotá 2009 - 2019, la cual involucra el fomento de las escuelas de deporte, los escenarios deportivos, los incentivos para los clubes, las recreovías y ciclovías entre muchas otras estrategias. Sin duda, esto permitirá el fortalecimiento del sector deportivo y generará múltiples oportunidades para diferentes productos y servicios.

Un punto interesante que debe resaltarse es que del porcentaje de personas restante que si practican actividad física y debido a las condiciones económicas y sociales que rodean el sector deportivo, se observa un desbalance entre la cantidad de personas que practican el deporte a nivel profesional y aquellas que lo hacen a nivel aficionado, siendo esto último la regla más que la excepción. Como se pudo establecer en el estudio realizado por nuestro grupo de investigación en el año 2008, existe una gran cantidad de clubes deportivos en diferentes disciplinas, cuya supervivencia ha dependido de los mismos consumidores, quienes son a la vez miembros e hinchas. De tal manera, el estudio presentado en este documento, pretende aportar al conocimiento de dichos consumidores y permitir a las organizaciones el contar con información valiosa para la planeación estratégica y el desarrollo de productos-servicios en el sector deportivo. El conocimiento de las características de los consumidores desempeña una función muy importante en muchas aplicaciones de mercadotecnia, dado que las diferencias encontradas entre los consumidores determinan igualmente estrategias diferenciales para el abordaje de dichos mercados. Las marcas existen para satisfacer las necesidades de los consumidores; estas necesidades sólo pueden satisfacerse hasta el grado en que los mercadólogos comprendan a las personas u organizaciones que usarán los bienes y servicios que están tratando de venderles y que lo hagan mejor que los competidores. Así por ejemplo, la información del comportamiento del consumidor puede ser utilizada para realizar una descripción específica del mercado actual y potencial de una marca. Esta segmentación se caracteriza por emplear como base criterios clasificatorios de índole psicográfico, que amplían los horizontes de la tradicional segmentación demográfica.

Con base en lo anterior, el objetivo del presente estudio fue establecer cuáles son las características del comportamiento de los consumidores de clubes deportivos de la ciudad de Bogotá, determinando sus características demográficas y psicográficas. Se pretendió así caracterizar y clasificar los conglomerados de usuarios en términos del género, nivel socio-económico, nivel educativo, estado civil y aspectos ocupacionales. Así mismo, se tuvo como objetivos el identificar el patrón de consumo de servicios ofertados por los clubes deportivos, los factores motivacionales asociados con la lealtad de los usuarios hacia los clubes, en las diferentes disciplinas deportivas y analizar el caso particular de los hinchas de equipos profesionales, tanto su perfil general como el nivel de involucramiento con el equipo. 


\section{Metodología}

\subsection{Tipo de investigación}

Se trató de una investigación descriptiva básica de carácter cuantitativo cuyo propósito fue caracterizar una población de consumidores o usuarios de clubes deportivos de la ciudad de Bogotá.

\subsection{Muestreo}

Debido a las características del proyecto y a las condiciones del sector en Bogotá, se realizó un Muestreo No Probabilístico por Racimos o Cuotas, el cual es una alternativa cuando por criterios prácticos y por el nivel de conocimiento del universo, no se pude realizar el Muestreo Aleatorio Estratificado. En este caso la idea fue estimar la proporción de clubes deportivos formales e informales en las diferentes disciplinas. Dado que no se tenía una idea precisa del tamaño del universo, se tomaron en cuenta los datos disponibles a partir de la caracterización ocupacional del 2006 de Coldeportes y las actualizaciones del IDRD en el 2007. Adicionalmente, se emplearon los datos obtenidos en el estudio de Crissien, Sandoval \& Cortés (2008) para estimar la proporción de clubes informales. En cada uno de los clubes seleccionados en la muestra, se tomó una proporción de consumidores actuales y se realizaron con ellos las entrevistas y encuestas. En total se obtuvo una muestra de 336 usuarios activos y finales de clubes deportivos correspondientes a diez disciplinas a saber: Fútbol, Artes Marciales, Patinaje, Natación, Baloncesto, Fútbol de Salón, Ciclismo, Tenis de Campo, Voleibol y Golf. Para tal efecto, se calculó que la muestra posee un nivel del $95 \%$ de confianza y 5,33\% de error.

\subsection{Instrumentos}

Se empleó una encuesta que incluía el conjunto de factores a evaluar. Las variables de estudio se relacionaron con aspectos demográficos, aspectos motivacionales, experiencias con los clubes, patrones de consumo y compra de servicios, artículos o ideas, perfil actitudinal, perfil de medios, expectativas y evaluación del servicio de los clubes deportivos.

\section{Resultados}

A través de todo el análisis de resultados, se define a los usuarios activos como aquellas personas que practican el deporte y son miembros (jugadores) de un club deportivo, mientras que se habla de usuarios finales cuando se hace referencia a las personas que presencian un evento deportivo (partido, competencia o espectáculo). Las encuestas realizadas con los usuarios de clubes fueron tabuladas y analizadas estadísticamente a través del paquete SPSS 16.0.

\section{Tabla 1}

Caracterización general de la muestra de usuarios activos y finales

\subsection{Perfil sociodemográfico general}

Tal como se puede apreciar en la tabla 1 , el 30,06\% de los participantes fueron usuarios activos, mientras que el $69,94 \%$ restante fueron usuarios finales. El $49 \%$ de los participantes correspondió a usuarios activos y finales de Fútbol, seguidos principalmente por las disciplinas de Artes Marciales $(9,2 \%)$, Patinaje (8\%), Natación (8,3\%) y Baloncesto (4,2\%).

\begin{tabular}{|c|c|c|c|c|c|}
\hline \multirow{3}{*}{$\begin{array}{l}\text { Tabla } 1 \\
\text { Caracterización } \\
\text { general de la muestra }\end{array}$} & \multirow{2}{*}{$\begin{array}{c}\text { Tipo de usuario } \\
\text { Disciplina deportiva }\end{array}$} & \multicolumn{2}{|c|}{ Activo } & \multicolumn{2}{|c|}{ Final } \\
\hline & & $\%$ Columna & Recuento & $\%$ Columna & Recuento \\
\hline & Fútbol & $50.5 \%$ & 51 & $49.4 \%$ & 116 \\
\hline de usuarios activos y & Artes marciales & $6.9 \%$ & 7 & $10.2 \%$ & 24 \\
\hline inales & Patinaje & $5.9 \%$ & 6 & $8.9 \%$ & 21 \\
\hline & Natación & $8.9 \%$ & 9 & $8.1 \%$ & 19 \\
\hline & Baloncesto & $6.9 \%$ & 7 & $3.0 \%$ & 7 \\
\hline & Fútbol de Salón & $5.0 \%$ & 5 & $2.6 \%$ & 6 \\
\hline & Ciclismo & $3.0 \%$ & 3 & $6.0 \%$ & 14 \\
\hline & Tenis de campo & $5.9 \%$ & 6 & $6.4 \%$ & 15 \\
\hline & Voleibol & $5.0 \%$ & 5 & $2.1 \%$ & 5 \\
\hline & Golf & $2.0 \%$ & 2 & $3.4 \%$ & 8 \\
\hline & Total & $30,06 \%$ & 101 & $69.94 \%$ & 235 \\
\hline
\end{tabular}

Fuente: elaboración propia a partir de datos del grupo de desarrollo regional del 
En el análisis de la edad de los usuarios, el rango donde se ubicaron la mayor cantidad de usuarios fue el de 15 a 24 años con un $47,73 \%$ de usuarios, seguido por un $25,08 \%$ en el rango entre 25 a 34 años y un $14,8 \%$ entre los 35 y 44 años. Se trata de una muestra de personas en su mayoría por debajo de los 35 años. Si se tiene en cuenta que la elección del entrevistado y el escenario en el que se realizaba la encuesta, fueron aleatorios, podemos concluir que las personas que son usuarios de los clubes son en su mayoría jóvenes. Esto es coherente con los datos disponibles respecto de prácticas deportivas y actividad física para la ciudad de Bogotá. Las tendencias identificadas en la muestra general con mayor participación en los tres primeros rangos de edad, tienden a mantenerse por disciplina especialmente en los casos de fútbol, natación, baloncesto, fútbol de salón, tenis de campo y golf.

En la comparación de los promedios de edad se observa una tendencia de participantes más jóvenes en los usuarios activos frente a los niveles reportados por los usuarios finales, con excepción del fútbol donde los promedios son similares, el fútbol de salón y el golf en los cuales los usuarios activos presentan niveles de edad promedio superior en comparación con los usuarios finales.

La distribución porcentual consolidada de los usuarios por género y disciplina se puede observar de manera detallada con la tabla 2. En el fútbol, fútbol de salón, tenis de campo, voleibol y golf, la mayoría de los participantes en el estudio fueron los hombres, mientras que en las disciplinas de artes marciales, natación, baloncesto y ciclismo la participación de las mujeres fue superior.

En el presente estudio, la mayoría de los usuarios pertenecen al estrato tres $(55,02 \%)$ seguido por el estrato cuatro $(24,01 \%)$ y en menor medida se identificaron usuarios pertenecientes al estrato dos (11,55\%), cinco $(6,38 \%)$, seis $(1,82 \%)$ y uno $(1,22 \%)$.

\begin{tabular}{|c|c|c|c|}
\hline & Tipo de usuario & Activo & Final \\
\hline & Genero & Femenino & Masculino \\
\hline $\begin{array}{l}\text { Disciplina } \\
\text { deportiva }\end{array}$ & Fútbol & $36.8 \%$ & $55.7 \%$ \\
\hline & Artes marciales & $11.3 \%$ & $8.3 \%$ \\
\hline & Patinaje & $16.0 \%$ & $4.3 \%$ \\
\hline & Natación & $15.1 \%$ & $5.2 \%$ \\
\hline & Baloncesto & $5.7 \%$ & $3.5 \%$ \\
\hline & Fútbol de Salón & $.9 \%$ & $4.3 \%$ \\
\hline & Ciclismo & $6.6 \%$ & $4.3 \%$ \\
\hline & Tenis de campo & $2.8 \%$ & $7.8 \%$ \\
\hline & Voleibol & $2.8 \%$ & $3.0 \%$ \\
\hline & Golf & $1.9 \%$ & $3.5 \%$ \\
\hline & Total & $100.0 \%$ & $100.0 \%$ \\
\hline
\end{tabular}

Tabla 2

Distribución muestral de los usuarios por disciplina y género
La tabla 3, permite ratificar la tendencia general de distribución por estrato tanto para el caso de los usuarios activos como el de los usuarios finales, observándose los mayores niveles de participación en el estrato tres (53,5\% y 55,7\%) respectivamente. Así mismo, el 63,36\% de los usuarios son solteros, seguidos principalmente por el $24,92 \%$ que corresponden a los usuarios casados y el 7,81\% quienes viven actualmente en unión libre. En cuanto al nivel educativo, la distribución muestra niveles de formación universitaria $(29,85 \%)$, secundaria $(26,27 \%)$ y estudiantes universitarios $(22,99 \%)$. Esta proporción es similar para usuarios activos y finales.
Por otra parte, solamente un $38,69 \%$ de los usuarios tiene hijos. De este porcentaje, el $27 \%$ corresponde a usuarios activos y el $43,8 \%$ a usuarios finales. En términos generales un $19 \%$ de los participantes reporta tener un hijo, un $12,5 \%$ dos hijos y el 5,36\% tres hijos. El número promedio de personas que conforman los hogares de los usuarios es de cuatro (con un $27,54 \%$ ) y oscila como tendencia general entre tres personas (con un 32,63\% que comprende la tendencia modal) y cinco personas (con un $13,77 \%$ ); la variabilidad en el número de personas va desde los hogares unipersonales, hasta los conformados por 12 personas. 
El 61,01\% de los usuarios cuenta con vivienda propia, el $21,13 \%$ vive actualmente en arriendo y un $17,86 \%$ tiene vivienda de tipo familiar. Particularmente un $57,4 \%$ de los usuarios activos y el $62,6 \%$ de los usuarios finales cuentan con vivienda propia. La distribución por localidades indica que los usuarios activos y finales son residentes de Engativá (27,2\%), Suba (17,3\%), Usaquén (7,1\%), Kennedy $(6,7 \%)$, Fontibón $(5,4 \%)$ y Barrios Unidos $(5,1 \%)$, principalmente.
En lo referente a los ingresos mensuales familiares de los hogares a los que pertenecen los usuarios encuestados, se identificó un ingreso medio de $\$ 2 ` 150.000$, el cual oscila entre $\$ 1^{\prime} 500.000$ y $\$ 3^{\prime} 500.000$. La figura 1 muestra los ingresos mensuales familiares promedio por disciplina y tipo de usuario.
Tabla 3

Caracterización por tipo de usuario y estrato

\begin{tabular}{|c|c|c|c|}
\hline \multicolumn{2}{|c|}{ Tipo de usuario } & Activo & Final \\
\hline Estrato & Uno & $1.0 \%$ & $1.3 \%$ \\
\hline & Dos & $14.1 \%$ & $10.4 \%$ \\
\hline & Tres & $53.5 \%$ & $55.7 \%$ \\
\hline & Cuatro & $22.2 \%$ & $24.8 \%$ \\
\hline & Cinco & $7.1 \%$ & $6.1 \%$ \\
\hline & Seis & $2.0 \%$ & $1.7 \%$ \\
\hline & Total & $100.0 \%$ & $100.0 \%$ \\
\hline
\end{tabular}

\section{Figura 1}

Comparación del ingreso mensual familiar por disciplina y tipo de usuario

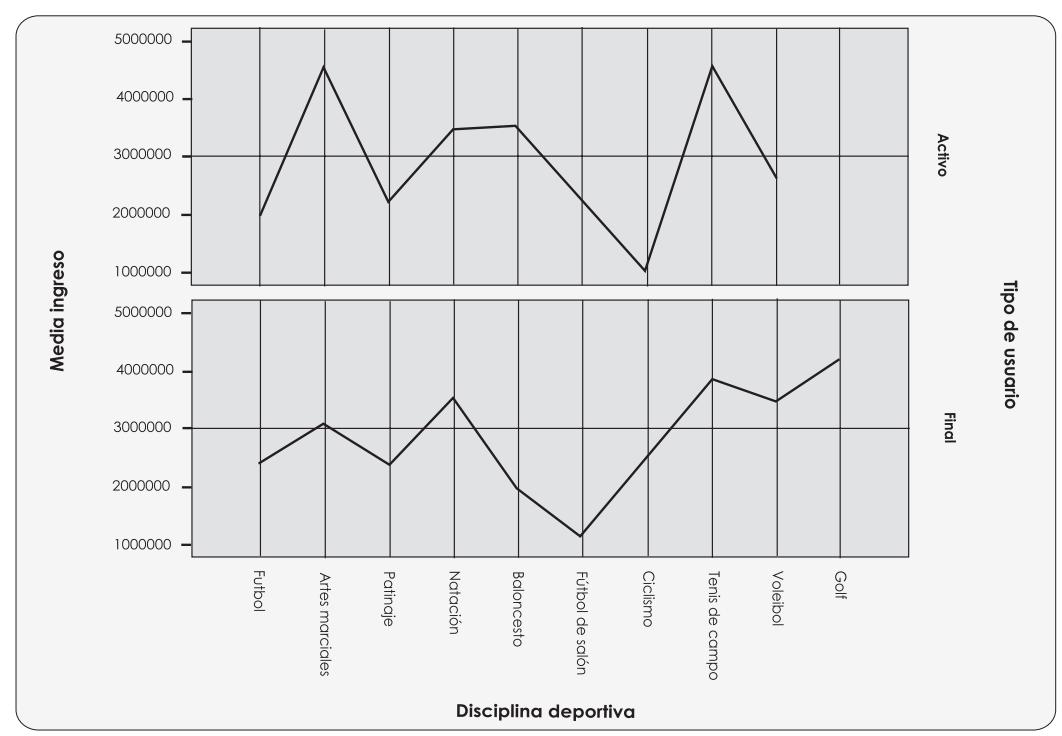

Se aprecia como los usuarios activos reportan ingresos mayores en las disciplinas de artes marciales, tenis de campo, baloncesto y natación; para el caso de los usuarios finales, los ingresos más elevados se observaron en espectadores de golf, tenis de campo, natación, voleibol y artes marciales. Adicionalmente, el $42,17 \%$ de los usuarios actualmente está trabajando, el 33,13\% estudia y un $18,98 \%$ estudia y trabaja simultáneamente. Un aspecto interesante es que los usuarios finales reportan con mayor frecuencia (45\%) trabajar mientras que una buena parte de los usuarios activos (39\%) estudian. La tabla 4 muestra la caracterización de estos aspectos laborales para ambos tipos de usuario. 


\begin{tabular}{|c|c|c|c|}
\hline & Tipo de usuario & Activo & Final \\
\hline \multirow[t]{6}{*}{ Ocupación } & Estudia & $38.6 \%$ & $30.2 \%$ \\
\hline & Trabaja & $33.7 \%$ & $45.1 \%$ \\
\hline & Estudia y trabaja & $26.7 \%$ & $15.3 \%$ \\
\hline & Hogar & $1.0 \%$ & $7.7 \%$ \\
\hline & N.R. & $.0 \%$ & $1.7 \%$ \\
\hline & Total & $100.0 \%$ & $100.0 \%$ \\
\hline \multirow[t]{5}{*}{ Vinculación } & Empleado & $40.6 \%$ & $44.3 \%$ \\
\hline & Independiente & $18.8 \%$ & $15.7 \%$ \\
\hline & Desempleado & $11.9 \%$ & $13.6 \%$ \\
\hline & N.R. & $28.7 \%$ & $26.4 \%$ \\
\hline & Total & $100.0 \%$ & $100.0 \%$ \\
\hline \multirow{5}{*}{$\begin{array}{l}\text { Tipo de } \\
\text { contrato }\end{array}$} & Definido & $13.9 \%$ & $10.6 \%$ \\
\hline & Indefinido & $22.8 \%$ & $28.5 \%$ \\
\hline & Servicios & $12.9 \%$ & $10.6 \%$ \\
\hline & N.R. & $50.5 \%$ & $50.2 \%$ \\
\hline & Total & $100.0 \%$ & $100.0 \%$ \\
\hline
\end{tabular}

Tabla 4

Caracterización de los aspectos laborales generales por tipo de usuario

\subsection{Pertenencia a clubes}

Debido a la composición de la muestra, la preferencia o pertenencia a los clubes deportivos posee la siguiente distribución por disciplina: a) Artes Marciales: Liga de Bogotá (29\%), Liga de Karate de Bogotá (16,1\%) y Sakura Liga de Bogotá (16,1\%); b) Patinaje: Club Alexandra Vivas (40\%), Club Tequendama $(11,1 \%)$ y Club Bacatá (11,1\%); c) Natación: Compensar (25\%), Water Polo (17,9\%) y Complejo Acuático (14,3\%); d) Baloncesto: Liga de Baloncesto (28,5\%), Ciclones $(14,3 \%)$ y Leopardos (14,3\%); e) Fútbol de Salón: Compensar (27,3\%), Dimitry (27,3\%), Cabaña, Club Rolabo, Codema, Corposibaté y Fondo Amigos 2009 (cada uno con 9,1\%); f) Ciclismo: Distaplass (23,5\%), Saltamontes $(23,5 \%)$ y Reto al Mundial $(17,6 \%)$; g) Tenis de Campo: Club de Tenis el Campín (23,8\%), La Estancia Serrezuela $(23,8 \%)$ y Federación Colombiana de Tenis (14,3\%); h) Voleibol: Selección Bogotá Juvenil (20\%), Liga de Voleibol (20\%), Club Canapro, Colsubsidio, Compensar, Escuela de Voleibol, Judebo, Jumpin Voley y Universidad Nacional (cada uno con $10 \%$ ); e i) Golf: Hato Grande (30\%), Federación Colombiana de Golf $(20 \%)$ y Farallones $(20 \%)$.

Es muy claro en este reporte de pertenencia a clubes deportivos, como las Ligas, cajas de compensación y escuelas deportivas ocupan un lugar importante en la mayoría de los deportes para los usuarios activos y para los usuarios finales. El $60 \%$ de los usuarios tiene entre 1 y 3 años de antigüedad en su correspondiente club, mientras que el $40 \%$ restante tiene cuatro años o más de antigüedad como miembro del club.

Se evidencia un lazo afectivo y familiar importante con el club, dado que en todas las disciplinas deportivas se reporta la participación en mayor o menor medida de otros miembros de la familia dentro del club Deportivo, esto es un indicador de la importancia estratégica que tiene el vínculo familiar como factor predictor en la pertenencia al mismo. Dentro del grupo de usuarios activos, se reporta una menor fidelidad hacia el Club actual. Un $42.9 \%$ de jugadores reportan haber pertenecido antes a otro club, mientas que en las otras disciplinas este porcentaje no sobrepasa el 12\% (ver tabla 5). Es muy poco frecuente que las personas desarrollen prácticas deportivas en diferentes disciplinas. Solamente el 25\% de jugadores de fútbol poseen este patrón. Por su parte, los usuarios finales o espectadores pueden estar vinculados a más de un club, principalmente en el caso del fútbol, artes marciales y patinaje.

Solamente un $18,75 \%$ de los participantes en el estudio reportó tener familiares considerados como deportistas de alto rendimiento. 


\section{Tabla 5}

Participación de los usuarios activos en otros clubes deportivos

\begin{tabular}{|l|l|c|c|c|}
\hline \multicolumn{5}{|c|}{ ¿Ha pertenecido a otros Clubes Deportivos como usuario activo? } \\
\hline & \multicolumn{1}{|c|}{ Género } & Si & No & Total \\
\hline Disciplina deportiva & Fútbol & $42.9 \%$ & $53.2 \%$ & $49.2 \%$ \\
\hline & Artes marciales & $10.3 \%$ & $8.3 \%$ & $9.1 \%$ \\
\hline & Patinaje & $6.3 \%$ & $9.3 \%$ & $8.2 \%$ \\
\hline & Natación & $11.9 \%$ & $6.3 \%$ & $8.5 \%$ \\
\hline & Baloncesto & $5.6 \%$ & $3.4 \%$ & $4.2 \%$ \\
\hline & Fútbol de Salón & $7.1 \%$ & $1.0 \%$ & $3.3 \%$ \\
\hline & Ciclismo & $4.0 \%$ & $5.9 \%$ & $5.1 \%$ \\
\hline & Tenis de campo & $7.1 \%$ & $5.9 \%$ & $6.3 \%$ \\
\hline & Voleibol & $4.0 \%$ & $2.4 \%$ & $3.0 \%$ \\
\hline & Golf & $.8 \%$ & $4.4 \%$ & $3.0 \%$ \\
\hline & Total & $100.0 \%$ & $100.0 \%$ & $100.0 \%$ \\
\hline
\end{tabular}

\subsection{Estilo de vida}

Se entiende por estilo de vida, la forma en la cual las personas gastan su tiempo y su dinero, pero también las opiniones y actitudes que poseen respecto de diferentes aspectos de su vida. Las actividades desarrolladas por usuarios activos y finales no difieren significativamente. De acuerdo con los demográficos, los usuarios activos estudian más horas a la semana, navegan más en internet y practican más deporte que los usuarios finales, esto es porque se trata de una muestra con un menor promedio de edad. Los hallazgos anteriores son coherentes con los estudios realizados en Alemania por Wicker, Breuer y Pawlowski (2009), donde la cantidad de tiempo semanal asignado a la práctica deportiva, correlaciona con el tipo de usuario.
En cuanto a la diversión, se observa una mayor frecuencia en la rumba por parte de los usuarios finales en comparación con el reporte de los usuarios activos. Los primeros rumbean hasta tres veces al mes, mientras que la frecuencia en los usuarios activos es una vez al mes o quincenal. La tabla 6, permite observar la frecuencia de asistencia a actividades culturales y recreativas. Se aprecia como la práctica deportiva es una forma de recreación mayor en usuarios activos que en usuarios finales, ya que los usuarios finales buscan sus fines recreativos asistiendo a parques.

\begin{tabular}{|l|l|c|c|c|}
\hline \multicolumn{2}{|c|}{ Tipo de usuario } \\
\hline & Activo & Final & Total \\
\hline $\begin{array}{c}\text { 1. Asiste al } \\
\text { Cine }\end{array}$ & Nunca & $12.1 \%$ & $15.3 \%$ & $14.4 \%$ \\
\hline & Rara vez & $25.3 \%$ & $32.3 \%$ & $30.2 \%$ \\
\hline & A veces & $43.4 \%$ & $36.6 \%$ & $38.6 \%$ \\
\hline & Frecuentemente & $19.2 \%$ & $15.7 \%$ & $16.8 \%$ \\
\hline & Total & $100.0 \%$ & $100.0 \%$ & $100.0 \%$ \\
\hline $\begin{array}{l}\text { 2. Asiste al } \\
\text { Conciertos y/o }\end{array}$ & Nunca & $27.3 \%$ & $33.3 \%$ & $31.5 \%$ \\
\hline & Rara vez & $36.4 \%$ & $37.6 \%$ & $37.2 \%$ \\
\hline & A veces & $30.3 \%$ & $21.4 \%$ & $24.0 \%$ \\
\hline & Frecuentemente & $6.1 \%$ & $7.7 \%$ & $7.2 \%$ \\
\hline & Total & $100.0 \%$ & $100.0 \%$ & $100.0 \%$ \\
\hline
\end{tabular}

Tabla 6

Asistencia a actividades culturales y recreativas por tipo de usuario 


\begin{tabular}{|c|l|c|c|c|}
\hline $\begin{array}{c}\text { 3. Asiste } \\
\text { a Parques } \\
\text { Recreativos }\end{array}$ & Nunca & $16.2 \%$ & $17.9 \%$ & $17.4 \%$ \\
\hline & Rara vez & $33.3 \%$ & $23.0 \%$ & $26.0 \%$ \\
\hline & A veces & $35.4 \%$ & $33.2 \%$ & $33.8 \%$ \\
\hline & Frecuentemente & $15.2 \%$ & $26.0 \%$ & $22.8 \%$ \\
\hline & Total & $100.0 \%$ & $100.0 \%$ & $100.0 \%$ \\
\hline $\begin{array}{c}\text { 4. Asiste } \\
\text { Deporneos }\end{array}$ & Nunca & $3.0 \%$ & $7.7 \%$ & $6.3 \%$ \\
\hline & Rara vez & $4.0 \%$ & $18.7 \%$ & $14.4 \%$ \\
\hline & A veces & $23.2 \%$ & $34.5 \%$ & $31.1 \%$ \\
\hline & Frecuentemente & $69.7 \%$ & $39.1 \%$ & $48.2 \%$ \\
\hline & Total & $100.0 \%$ & $100.0 \%$ & $100.0 \%$ \\
\hline
\end{tabular}

Continuación:Tabla 6

Asistencia a actividades culturales y recreativas por tipo de usuario
En cuanto al perfil actitudinal de los grupos estudiados, se observa en los usuarios activos un perfil muy tradicional, con un fuerte énfasis actitudinal positivo hacia el deporte y la vida saludable. La mayoría de las personas creen en Dios y consideran la familia como un eje central en sus vidas. Las opiniones de los usuarios finales evidencian que le otorgan una menor importancia a la práctica deportiva dentro de sus vidas, pero valoran el poseer una vida saludable. Como los usuarios activos son religiosos y consideran la familia como lo más importante de su vida. Las afirmaciones que recibieron mayor rechazo por parte de usuarios activos y finales fueron las relacionadas con la aceptación del suicidio como opción y el cambiar de pareja frecuentemente. Se evidencia entonces un perfil conservador en ambos tipos de usuarios.

Los jugadores y espectadores encuestados manifiestan un alto nivel de satisfacción con su estilo de vida. No obstante, algunos aspectos resultaron más satisfactorios para los usuarios activos. Tal es el caso del estado del ánimo con un nivel de satisfacción promedio para los usuarios activos de (4.37), apariencia física con un promedio de (4.38) y cumplimiento de metas propuestas con un promedio de (4.00). A los usuarios finales les preocupa un poco más los aspectos económicos de su vida. Al parecer, los usuarios activos tienen una vida más satisfactoria que los usuarios finales. En el caso de los usuarios de clubes de fútbol, los usuarios activos presentan niveles levemente superiores (3.6 a 4.4) frente a los usuarios finales (3.5 a 4.2) en casi todas las áreas de satisfacción con excepción del área de logros académicos.
En relación con el nivel de estrés que experimentan los jugadores y espectadores, se encuentra que los usuarios activos reportan menores niveles de estrés en las disciplinas de fútbol, artes marciales, patinaje, baloncesto, fútbol de salón, ciclismo, tenis de campo, voleibol y golf (Ver Tabla 7).

\subsection{Aspectos médicos y salud}

La relación estatura- peso presenta un promedio general en la muestra de 1,70 cms. y $65 \mathrm{Kg}$, oscilando entre 1,65 y 1,76 cms., para el caso de la estatura, y entre 58 a $74 \mathrm{Kg}$., para el caso del peso. En los usuarios activos la estatura promedio es de 1,71 cms., mientras que en los finales es de 1,69 cms., presentándose una diferencia estadísticamente significativa (t:1,98; sig:.048). Los promedios de estatura de usuarios activos de tenis, voleibol y baloncesto fueron mayores. Adicionalmente, los promedios de peso reportados en los usuarios activos fueron superiores en ciclismo (71,3 Kg.), fútbol de salón (71 Kg.) y golf (69 Kg.).

La mayoría de jugadores y espectadores calificaron su salud como excelente. Los usuarios activos con mayor número de visitas al médico durante el año son los de artes marciales $(7,5)$, seguidos por los de natación $(4,8)$ y baloncesto $(3,9)$. Estos datos se complementan con el número de incapacidades que se solicitan en promedio al año; también los practicantes de artes marciales tienen promedios más altos con tres incapacidades anuales, seguidos por los de fútbol con un promedio de $(1,5)$ incapacidades anuales. El número de incapacidades anuales de los usuarios finales es menor. Los trastornos médicos más frecuentes en jugadores activos son las lesiones musculares y los problemas articulares. 


\section{Tabla 7}

Comparación de niveles de estrés por disciplina y tipo de usuario

\begin{tabular}{|c|c|c|c|c|c|c|}
\hline \multicolumn{7}{|c|}{ Estadísticos de grupo } \\
\hline \multirow{2}{*}{$\begin{array}{c}\begin{array}{c}\text { Disciplina } \\
\text { deportiva }\end{array} \\
\text { Fútbol }\end{array}$} & \multirow{2}{*}{$\begin{array}{c}\text { Tipo de Usuario } \\
\text { Nivel general de estrés }\end{array}$} & \multirow{2}{*}{$\begin{array}{c}\mathrm{N} \\
\text { Activo }\end{array}$} & \multirow{2}{*}{$\begin{array}{c}\text { Media } \\
51\end{array}$} & \multirow{2}{*}{$\begin{array}{c}\begin{array}{c}\text { Desviación } \\
\text { típ. }\end{array} \\
4.69\end{array}$} & \multicolumn{2}{|c|}{ Error típ. de la media } \\
\hline & & & & & 2.619 & .367 \\
\hline & & Final & 116 & 4.89 & 2.355 & .219 \\
\hline \multirow[t]{2}{*}{ Artes Marciales } & Nivel general de estrés & Activo & 7 & 4.29 & 2.690 & 1.017 \\
\hline & & Final & 24 & 5.67 & 2.632 & .537 \\
\hline \multirow[t]{2}{*}{ Patinaje } & Nivel general de estrés & Activo & 6 & 4.50 & 1.871 & .764 \\
\hline & & Final & 21 & 4.67 & 1.958 & .427 \\
\hline \multirow[t]{2}{*}{ Natación } & Nivel general de estrés & Activo & 9 & 5.89 & 2.667 & .889 \\
\hline & & Final & 19 & 5.79 & 2.440 & .560 \\
\hline \multirow[t]{2}{*}{ Baloncesto } & Nivel general de estrés & Activo & 7 & 5.43 & 2.820 & 1.066 \\
\hline & & Final & 7 & 5.86 & 1.676 & .634 \\
\hline \multirow[t]{2}{*}{ Fútbol de Salón } & Nivel general de estrés & Activo & 5 & 3.20 & 2.683 & 1.200 \\
\hline & & Final & 6 & 5.50 & .837 & .342 \\
\hline \multirow[t]{2}{*}{ Ciclismo } & Nivel general de estrés & Activo & 3 & 2.33 & .577 & .333 \\
\hline & & Final & 14 & 6.07 & 2.093 & .559 \\
\hline \multirow[t]{2}{*}{ Tenis de Campo } & Nivel general de estrés & Activo & 6 & 3.83 & 3.189 & 1.302 \\
\hline & & Final & 15 & 4.67 & 2.526 & .652 \\
\hline \multirow[t]{2}{*}{ Voleibol } & Nivel general de estrés & Activo & 5 & 4.60 & 1.673 & .748 \\
\hline & & Final & 5 & 4.40 & 3.050 & 1.364 \\
\hline \multirow[t]{2}{*}{ Golf } & Nivel general de estrés & Activo & 2 & 2.50 & 2.121 & 1.500 \\
\hline & & Final & 8 & 4.75 & 1.581 & .559 \\
\hline
\end{tabular}

Se encontró que una parte importante de usuarios consumen cigarrillo. El promedio para activos es de $3.8 \mathrm{y}$ para finales es de 4.1. Por disciplina, se encontró que a nivel de los usuarios activos los primeros lugares son ocupados por los jugadores de golf $(50 \%)$, patinaje $(33,3 \%)$ y fútbol de salón (20\%); mientras que en los usuarios finales el primer lugar lo ocupan los usuarios de fútbol de salón $(83,3 \%)$, seguidos por los de patinaje $(23,8 \%)$ y los de fútbol $(20,7 \%)$. Con referencia al consumo de sustancias psicoactivas cabe anotar que los reportes más significativos se encuentran en los usuarios activos (40\%) y finales (83\%) de fútbol de salón, principalmente.

\subsection{Perfil de usuario activo de clubes deportivos}

Para facilitar la construcción de un perfil diferencial de usuarios activos y finales, a continuación se presenta una caracterización específica para usuarios activos. Se consideraron aquí 101 usuarios activos pertenecientes a las diferentes disciplinas. La edad promedio de inicio en la práctica deportiva para los usuarios activos en general es cercana a los 13 años. La disciplina que reporta un inicio más temprano es la natación (10 años), y las de inicio más tardío son voleibol (17 años), ciclismo (18 años) y golf (23 años).

Respecto de las influencias que afectaron la pertenencia al club, se encuentra que en el fútbol, las artes marciales, el golf, el ciclismo y el voleibol, un miembro del club sirvió como influenciador. En el patinaje y la natación, la publicidad fue una variable importante y en el tenis de campo, la competencia deportiva permitió que hicieran contacto con el club. Para los jugadores es muy importante que sus familias les acompañen a las competencias y prácticas deportivas. De a 1 a 10, calificaron la importancia en 7.4, siendo mayor para deportistas de natación (9.0), voleibol y fútbol de salón (cada uno con 8.4) y fútbol con (7.5). Para los jugadores, el club representa un aspecto muy importante de sus vidas; ellos indicaron que se 
encontraban orgullosos de su club, que desean que sus hijos pertenezcan a él, consideran a sus compañeros como parte de su familia y le dan a su práctica deportiva una gran importancia para crecer y manejar sus problemas personales.

Los usuarios activos practican el deporte de su elección varias horas a la semana: a) Fútbol, 9.2 hrs.; b) Artes Marciales, 18.7 hrs.; c) Patinaje, 8.2 hrs.; d) Natación, 11.7 hrs.; e) Baloncesto, 11.4 hrs.; f) Fútbol de Salón, 6.4 hrs.; g) Ciclismo, 13.3 hrs.; h) Tenis de Campo, 11.3 hrs.; i) Voleibol, 5.8 hrs.; y j) Golf, 6 hrs. Los deportes con mayor frecuencia mensual de entrenamiento son las artes marciales, el tenis de campo, el ciclismo, el fútbol y la natación, pero el deporte donde los jugadores participan en más torneos mensuales es el patinaje. La tabla 8 muestra que en general, los clubes realizan pocas reuniones mensuales con sus miembros, la frecuencia más alta se observa para la natación.

\section{Tabla 8}

Prácticas de

entrenamiento, torneos

y reuniones sociales

mensuales del club

\begin{tabular}{|c|c|c|c|c|}
\hline & & $\begin{array}{l}\text { ¿Cuántas veces al mes } \\
\text { realiza prácticas de } \\
\text { entrenamiento formal } \\
\text { habitualmente con el } \\
\text { club? }\end{array}$ & $\begin{array}{c}\text { ¿Cuántos torneos } \\
\text { en el año } \\
\text { desarrolla con el } \\
\text { club? }\end{array}$ & $\begin{array}{c}\text { ¿Cuántas reuniones } \\
\text { sociales realiza con } \\
\text { personas del club } \\
\text { en promedio } \\
\text { mensualmente? }\end{array}$ \\
\hline \multirow{12}{*}{$\begin{array}{l}\text { Disciplina } \\
\text { deportiva }\end{array}$} & & Media & Media & Media \\
\hline & Fútbol & 11.8 & 3.5 & 1.9 \\
\hline & Artes marciales & 22.9 & 3.4 & .9 \\
\hline & Patinaje & 9.0 & 8.5 & .7 \\
\hline & Natación & 11.7 & 6.8 & 2.6 \\
\hline & Baloncesto & 9.7 & 4.1 & 1.0 \\
\hline & Fútbol de salón & 6.6 & 2.4 & .4 \\
\hline & Ciclismo & 11.7 & 8.0 & 1.7 \\
\hline & Tenis de campo & 15.3 & 5.3 & 1.8 \\
\hline & Voleibol & 5.2 & 2.0 & .8 \\
\hline & Golf & 8.0 & 6.0 & .5 \\
\hline & Total & 11.8 & 4.3 & 1.6 \\
\hline
\end{tabular}

en torneos corresponden a la natación y al fútbol (ver tabla 9). Algunos jugadores reciben ingresos por parte de sus clubes. Solamente se reportaron ingresos promedio mensuales en las disciplinas de fútbol (\$672.500), fútbol de salón $(\$ 200.000)$ y tenis de campo (\$800.000).

\section{Tabla 9}

Costos asociados con la participación en el Club Deportivo

\begin{tabular}{|c|c|c|c|c|}
\hline & $\begin{array}{l}\text { a) Costos } \\
\text { Matrícula }\end{array}$ & $\begin{array}{l}\text { b) Costos } \\
\text { Pensión }\end{array}$ & $\begin{array}{l}\text { c) Cuota promedio } \\
\text { torneos }\end{array}$ \\
\hline & & Media & Media & Media \\
\hline \multirow{11}{*}{$\begin{array}{l}\text { Disciplina } \\
\text { deportiva }\end{array}$} & Fútbol & 214545 & 107500 & 71684 \\
\hline & Artes marciales & 7500 & 38500 & 32500 \\
\hline & Patinaje & 51000 & 41250 & 16500 \\
\hline & Natación & 94000 & 94000 & 116667 \\
\hline & Baloncesto & 47500 & 30000 & 14500 \\
\hline & Fútbol de salón & 30000 & 20000 & 17500 \\
\hline & Ciclismo & . & . & 50000 \\
\hline & Tenis de campo & 500000 & 310000 & 40000 \\
\hline & Voleibol & 60000 & 50000 & . \\
\hline & Golf & & & \\
\hline & Total & 129207 & 92743 & 58486 \\
\hline
\end{tabular}


La tabla 10 muestra que los clubes apoyan a los jugadores con becas y con implementos deportivos. Las becas son usuales en baloncesto, tenis de campo y voleibol. En el caso del fútbol, el $73 \%$ de los jugadores reciben apoyo con los implementos deportivos y en tenis de campo el $100 \%$ de entrevistados también reciben este tipo de ayuda.
Tabla 10

Apoyo del Club

Deportivo con becas

e implementos

deportivos

\begin{tabular}{|c|c|c|c|c|c|}
\hline & \multicolumn{2}{|c|}{$\begin{array}{l}\text { ¿Recibe usted alguna beca } \\
\text { por parte del club? }\end{array}$} & \multicolumn{3}{|c|}{$\begin{array}{c}\text { ¿El club lo apoya con implementos } \\
\text { deportivos? }\end{array}$} \\
\hline \multirow{10}{*}{$\begin{array}{l}\text { Disciplina } \\
\text { deportiva }\end{array}$} & & Si & No & $\mathrm{Si}$ & No \\
\hline & Fútbol & $26.7 \%$ & $73.3 \%$ & $73.3 \%$ & $26.7 \%$ \\
\hline & Artes marciales & $.0 \%$ & $100.0 \%$ & $.0 \%$ & $100.0 \%$ \\
\hline & Patinaje & $.0 \%$ & $100.0 \%$ & $.0 \%$ & $100.0 \%$ \\
\hline & Natación & $33.3 \%$ & $66.7 \%$ & $28.6 \%$ & $71.4 \%$ \\
\hline & Baloncesto & $75.0 \%$ & $25.0 \%$ & $25.0 \%$ & $75.0 \%$ \\
\hline & Fútbol de salón & $.0 \%$ & $100.0 \%$ & $50.0 \%$ & $50.0 \%$ \\
\hline & Ciclismo & $.0 \%$ & $100.0 \%$ & $50.0 \%$ & $50.0 \%$ \\
\hline & Tenis de campo & $50.0 \%$ & $50.0 \%$ & $100.0 \%$ & $.0 \%$ \\
\hline & Voleibol & $50.0 \%$ & $50.0 \%$ & $50.0 \%$ & $50.0 \%$ \\
\hline & Total & $27.5 \%$ & $72.5 \%$ & $50.0 \%$ & $50.0 \%$ \\
\hline
\end{tabular}

En relación con la marca favorita de ropa deportiva se presentaron solamente 42 menciones y en ellas se destaca en primer lugar Adidas (27,7\%), seguida por Nike (13,9\%), Speedo (5\%) y Puma (4\%). Por disciplina, los reportes asociados con el número de veces que los deportistas compran ropa al año está en un promedio de 2.5 veces siendo superior para los casos de tenis de campo (4.2 veces), voleibol (4.0 veces) y golf ( 3.5 veces). Adicionalmente, al año, los promedios de inversión en implementos deportivos a nivel de alta competencia para el caso del patinaje son $\$ 1^{\prime} 087.500$, seguidos por tenis de campo con $\$ 634.000$, golf $\$ 600.000$ y natación $\$ 566.666$.

\subsection{Perfil de usuario final de clubes deportivos}

Se presentan los principales hallazgos derivados de la caracterización de los 235 usuarios finales, que comprenden un conjunto de espectadores, aficionados e hinchas de los Clubes Deportivos, que en algunos casos son adicionalmente familiares o amigos de un usuario activo o deportista y tienen la oportunidad de acompañarle como parte de las actividades tradicionales de esparcimiento y recreación del núcleo familiar.

Se observa que el $11,5 \%$ de ellos tiene algún tipo de vínculo con los directivos del club y este aspecto se resalta especialmente en baloncesto (42,9\%), ciclismo $(21,4 \%)$ y voleibol (20\%). Adicionalmente un $10,2 \%$ de los aficionados es socio formal del club, principalmente en el caso de tenis de campo (53,3\%) y golf (25\%). Un $67 \%$ de los usuarios finales se consideran fans o hinchas del club y esta característica se resalta principalmente en las disciplinas de voleibol (80\%), fútbol $(78,4 \%)$ y baloncesto $(71,4 \%)$.

Adicionalmente, en el presente estudio un $42,1 \%$ de los usuarios finales reporta ser familiar de algún jugador y en particular corresponde a las madres, hijos, padres y otros familiares del deportista con niveles porcentuales entre el $8 \%$ y el $9 \%$. Las disciplinas en las cuales existe una mayor tendencia a que los usuarios finales asistan acompañados son el fútbol y el voleibol ( 5 personas en promedio para cada caso), seguidas por el ciclismo con un promedio cercano a 4 personas y las disciplinas de tenis de campo, artes marciales y golf ( 3 personas en promedio para cada caso). Los espectadores que permanecen más tiempo en promedio en los escenarios deportivos son los que asisten a tenis de campo (6 hrs.), seguidos por los espectadores del golf ( $4.3 \mathrm{hrs}$.), los aficionados al voleibol y la natación (cada uno con $3.6 \mathrm{hrs}$., en promedio) y los fans o hinchas que asisten al fútbol ( $3 \mathrm{hrs}$.).

Los usuarios finales pueden ser considerador heavy users del espectáculo deportivo que prefieren. La tabla 11 muestra que el caso más frecuente es que asistan más de una vez a la semana a los escenarios deportivos. 


\begin{tabular}{|c|c|c|c|c|c|c|}
\hline \multicolumn{7}{|c|}{ ¿Con qué frecuencia asiste a este tipo de eventos? } \\
\hline & & $\begin{array}{c}\text { Cada dos } \\
\text { meses o } \\
\text { menos }\end{array}$ & Mensualmente & Quincenalmente & $\begin{array}{r}\text { Una vez a } \\
\text { la semana }\end{array}$ & $\begin{array}{c}\text { Más de } \\
\text { una vez } \\
\text { a la } \\
\text { semana }\end{array}$ \\
\hline \multirow{11}{*}{$\begin{array}{l}\text { Disciplina } \\
\text { deportiva }\end{array}$} & Fútbol & $22.4 \%$ & $19.8 \%$ & $25.9 \%$ & $21.6 \%$ & $10.3 \%$ \\
\hline & Artes marciales & $4.2 \%$ & $4.2 \%$ & $16.7 \%$ & $29.2 \%$ & $45.8 \%$ \\
\hline & Patinaje & $4.8 \%$ & $4.8 \%$ & $.0 \%$ & $28.6 \%$ & $61.9 \%$ \\
\hline & Natación & $5.6 \%$ & $16.7 \%$ & $22.2 \%$ & $38.9 \%$ & $16.7 \%$ \\
\hline & Baloncesto & $.0 \%$ & $14.3 \%$ & $14.3 \%$ & $14.3 \%$ & $57.1 \%$ \\
\hline & Fútbol de salón & $.0 \%$ & $33.3 \%$ & $33.3 \%$ & $16.7 \%$ & $16.7 \%$ \\
\hline & Ciclismo & $.0 \%$ & $7.1 \%$ & $7.1 \%$ & $21.4 \%$ & $64.3 \%$ \\
\hline & Tenis de campo & $6.7 \%$ & $.0 \%$ & $6.7 \%$ & $20.0 \%$ & $66.7 \%$ \\
\hline & Voleibol & $.0 \%$ & $20.0 \%$ & $.0 \%$ & $.0 \%$ & $80.0 \%$ \\
\hline & Golf & $28.6 \%$ & $.0 \%$ & $14.3 \%$ & $42.9 \%$ & $14.3 \%$ \\
\hline & Total & $13.7 \%$ & $14.2 \%$ & $18.9 \%$ & $24.0 \%$ & $29.2 \%$ \\
\hline
\end{tabular}

Tabla 11

Frecuencia de asistencia a los eventos deportivos por disciplina
Los espectadores o usuarios finales reportan que los costos que deben sufragar cuando asisten a los eventos corresponden principalmente a alimentos como agua $(66,8 \%)$; otro gasto es el pago por usar los baños $(48,5 \%)$. La tabla 12, presenta los costos promedio relacionados con la asistencia a los eventos deportivos específicamente en la compra de alimentos, el uso del servicio de parqueadero, la compra de boletas, el uso de los baños y el servicio de transporte.

De otra parte, los amigos son la mejor fuente de información relacionada con la programación y divulgación de los eventos deportivos, con una tendencia general del 55,3\% la cual se mantiene en la mayoría de las disciplinas deportivas, seguida por los familiares que son deportistas con un $20,4 \%$.

Según el reporte de los espectadores, en un $60,4 \%$ de los casos NUNCA se finaliza tomando alguna bebida alcohólica por parte de los usuarios finales, mientras que en un $23,8 \%$ de los casos esta práctica ocurre RARA VEZ. En particular se observa que un $16,7 \%$ de los aficionados al fútbol de salón FRECUENTEMENTE finalizan consumiendo alguna bebida alcohólica y en un $66,7 \%$ sucede A VECES.

\section{Tabla 12}

Costos promedio de alimentos y servicios en eventos deportivos por disciplina
¿Con qué frecuencia asiste a este tipo de eventos?

\begin{tabular}{|c|c|c|c|c|c|c|}
\hline & Alimentos & Parqueadero & Boleta & Baños & Transporte \\
\hline & & Media & Media & Media & Media & Media \\
\hline \multirow{11}{*}{$\begin{array}{l}\text { Disciplina } \\
\text { Deportiva }\end{array}$} & Fútbol & 9,993 & 5,447 & 20,545 & 911 & 7,060 \\
\hline & Artes marciales & 7,711 & 5,625 & . & 900 & 7,537 \\
\hline & Patinaje & 8,393 & 6,011 & 18,250 & 1,088 & 6,420 \\
\hline & Natación & 10,188 & 4,063 & . & 500 & 11,364 \\
\hline & Baloncesto & 10,500 & 4,767 & 12,500 & 2,000 & 14,200 \\
\hline & Fútbol de salón & 5,333 & . & . & . & 3,200 \\
\hline & Ciclismo & 13,071 & 5,429 & . & 2,500 & 11,600 \\
\hline & Tenis de campo & 12,231 & 3,333 & . & 1,000 & 9,257 \\
\hline & Voleibol & 7,000 & 4,000 & 20,000 & 1,000 & 5,800 \\
\hline & Golf & 8,143 & 6,000 & . & 1,000 & 5,000 \\
\hline & Total & 9,820 & 5,190 & 19,900 & 1,147 & 7,652 \\
\hline
\end{tabular}




\subsection{Perfil de los usuarios finales de los clubes deportivos de fútbol bogotanos: Santafé, Millonarios y La Equidad}

De manera intencional, se seleccionaron 86 hinchas de los tres clubes capitalinos. La idea fue caracterizar y diferenciar algunos aspectos de su perfil. Se entrevistaron 31 hinchas de Millonarios, 29 de Santafé y 26 de La
Equidad. Los fans de Santafé y Millonarios fueron más jóvenes que los hinchas de La Equidad. La tabla 13 permite observar que un 54,1\% de los hinchas vive en el estrato tres y esta tendencia mayoritaria por estrato se mantiene para cada uno de los tres Clubes Deportivos, en segunda instancia se encuentra la participación del estrato cuatro con un $24,7 \%$, seguida por el estrato dos con un $11,8 \%$. La Equidad tiene un menor porcentaje de hinchas de estratos 1 y 2 y un porcentaje más alto de estratos 5 y 6 .

\section{Tabla 13}

Usuarios finales de Santafé, Millonarios y La Equidad por estrato

\begin{tabular}{|c|c|c|c|c|c|}
\hline \multicolumn{7}{|c|}{ Usuarios Finales Clubes de Fútbol } \\
\hline \multirow{4}{*}{} & & Santafé & Millonarios & La Equidad & Total \\
\hline \multirow{4}{*}{ Estrato } & Uno & $3.4 \%$ & $3.2 \%$ & $.0 \%$ & $2.4 \%$ \\
\cline { 2 - 6 } & Dos & $13.8 \%$ & $12.9 \%$ & $8.0 \%$ & $11.8 \%$ \\
\cline { 2 - 6 } & Tres & $58.6 \%$ & $51.6 \%$ & $52.0 \%$ & $54.1 \%$ \\
\cline { 2 - 6 } & Cuatro & $17.2 \%$ & $29.0 \%$ & $28.0 \%$ & $24.7 \%$ \\
\cline { 2 - 6 } & Cinco & $3.4 \%$ & $3.2 \%$ & $8.0 \%$ & $4.7 \%$ \\
\cline { 2 - 6 } & Seis & $3.4 \%$ & $.0 \%$ & $4.0 \%$ & $2.4 \%$ \\
\cline { 2 - 6 } & Total & $100.0 \%$ & $100.0 \%$ & $100.0 \%$ & $100.0 \%$ \\
\hline
\end{tabular}

En cuanto al nivel educativo, se resalta la participación de los universitarios $(47,7 \%)$ y en segunda instancia de personas con formación secundaria $(27,9 \%)$, esta tendencia se mantiene en cada uno de los tres clubes. Santafé posee más hinchas de secundaria que los otros dos clubes y La Equidad posee el menor porcentaje de los tres. De la misma manera, La Equidad posee el mayor porcentaje de hinchas con formación de postgrado y profesionales, confirmándose el hecho que la fanaticada de este Club principalmente proviene de las empresas patrocinadoras. Un $18 \%$ de hinchas entrevistados son socios del club o poseen vínculos con las directivas.

El estilo de vida de los hinchas no difiere significativamente del perfil general de usuarios finales presentado en este documento. Se resalta que el $48 \%$ de hinchas de Santafé rumbean más de una vez a la semana, que los fans de La Equidad reportan mayores niveles de estrés y de consumo de cigarrillo. En cuanto al perfil general de satisfacción con diferentes áreas de la vida para los hinchas de Santafé la más satisfactoria fue la familiar (4.3), seguida por la sexualidad y el estado de ánimo cada una con (4.1), mientras que el área de menor satisfacción es la religión y vida espiritual con (3.5). En cuanto al perfil general de satisfacción para los hinchas de Millonarios, se puede apreciar que el área de mayor satisfacción es la sexualidad con (4.3), seguida por el área familiar con (4.2) y el área de diversión y recreación con (4.1), también el área de menor satisfacción es la religión y vida espiritual con (3.2). Los hinchas de La Equidad presentan un mayor nivel de satisfacción en el área familiar con (4.5), seguida por la apariencia física con (4.3) y las áreas de logros académicos, diversión y recreación con (4.2), a diferencia de las áreas de menor satisfacción que corresponden a los aspectos económicos, la religión y vida espiritual con (3.7).

En cuanto a los hábitos de consumo, los hinchas asisten a eventos cada dos meses $(29,1 \%)$, quincenalmente $(27,1 \%)$ y mensualmente $(23,3 \%)$. En particular los hinchas de Santafé asisten cada quince días (37,9\%), los hinchas de Millonarios cada dos meses (48,4\%) y los hinchas de La Equidad mensualmente (30,8\%). Este comportamiento presenta una asociación estadísticamente significativa con valores (X2g1.8: 16.503 y sig: .036) (ver tabla 14). 


\section{Tabla 14}

Frecuencia de asistencia a los eventos deportivos reportada por los usuarios finales de Santafé, Millonarios y La Equidad

\section{Tabla 15}

Importancia del acompañamiento a los eventos deportivos en familia por parte de los usuarios finales de Santafé, Millonarios y La Equidad

\section{Usuarios Finales Clubes de Fútbol}

\begin{tabular}{|c|c|c|c|c|c|}
\hline \multicolumn{2}{|c|}{} & Santafé & Millonarios & La Equidad & Total \\
\hline \multirow{2}{*}{$\begin{array}{c}\text { ¿Con qué } \\
\text { frecuencia } \\
\text { asiste a } \\
\text { este tipo de } \\
\text { eventos? }\end{array}$} & Cada dos meses & $10.3 \%$ & $48.4 \%$ & $26.9 \%$ & $29.1 \%$ \\
\cline { 2 - 6 } & Mensualmente & $20.7 \%$ & $19.4 \%$ & $30.8 \%$ & $23.3 \%$ \\
\cline { 2 - 6 } & $\begin{array}{c}\text { Una vez a la } \\
\text { semana }\end{array}$ & $24.1 \%$ & $3.2 \%$ & $23.1 \%$ & $27.9 \%$ \\
\cline { 2 - 6 } & $\begin{array}{c}\text { Más de una vez a } \\
\text { la semana }\end{array}$ & $6.9 \%$ & $6.5 \%$ & $.0 \%$ & $15.1 \%$ \\
\hline & Total & $100.0 \%$ & $100.0 \%$ & $100.0 \%$ & $100.0 \%$ \\
\hline
\end{tabular}

\begin{tabular}{|c|c|c|c|c|}
\hline \multicolumn{4}{|c|}{ Usuarios Finales Clubes de Fútbol } \\
\hline & Santafé & Millonarios & La Equidad & Total \\
\hline $\begin{array}{c}\text { ¿Qué tan importante es para usted el } \\
\text { hecho de sentir que puede acompañar } \\
\text { a su familiar en estos eventos? }\end{array}$ & 5.5 & 5.6 & 7.9 & 6.3 \\
\hline $\begin{array}{c}\text { ¿Qué tanto cree que esta oportunidad } \\
\text { de compartir en torno al deporte } \\
\text { permite que la familia se integre } \\
\text { más? }\end{array}$ & 5.8 & 5.8 & 8.1 & 6.5 \\
\hline $\begin{array}{c}\text { ¿Qué tanto cree que su familia } \\
\text { disfruta cuando asiste a estos eventos } \\
\text { y prácticas deportivas? }\end{array}$ & 6.5 & 5.9 & 7.8 & 6.7 \\
\hline
\end{tabular}

Finalmente, se puede afirmar que los hinchas de equipos profesionales de fútbol muestran un alto involucramiento con el Club. Manifiestan un alto vínculo emocional y consideran que deben lograr que sus hijos y familia tengan su misma afición. 


\section{Conclusiones}

$\mathbf{L}^{\mathrm{a}}$ a investigación presentada en este artículo comprende información valiosa para el conocimiento y abordaje de los consumidores de clubes deportivos en Bogotá.

En primera instancia, se podría afirmar categóricamente que existen un conjunto de diferencias significativas entre los usuarios activos y finales de los clubes, en la mayoría de disciplinas investigadas. A partir del reporte de cada uno de los dos segmentos, se evidencia que el estado físico de las personas que practican deporte amateur como usuarios activos es mejor que en los usuarios finales. Así mismo, los indicadores asociados con problemas de salud, como el peso, las visitas al médico y las incapacidades son mayores en los usuarios finales.

De forma correlacionada, los usuarios activos manifiestan una mayor satisfacción en las distintas áreas vitales y un menor nivel de estrés general. Poseen por tanto un estilo de vida más saludable. También su perfil actitudinal demuestra una fuerte relación con el deporte y una alta valoración tanto del club al que pertenecen como del estilo de vida saludable. Este no es el compromiso de las usuarios finales, quienes en concordancia con nuestras hipótesis previas, asisten como una forma de apoyo a su familia o al club, y poseen fines lúdicos. Se evidencian entonces perfiles motivacionales distintos para usuarios activos y finales.

Respecto de los aspectos económicos, se encontró que los usuarios activos pagan sumas de dinero importantes para ingresar, mantenerse y participar en las actividades del club al que pertenecen. Esta cantidad de dinero varía dependiendo del deporte, hallazgo coincidente con el estudio de Wiecker, Breuer y Pawlowski (2009). También en nuestro estudio se ve como algunos deportes implican costos altos (tenis, golf, etc.), los cuales segmentan a los practicantes, pero también se ve el caso de deportes como el fútbol, que presenta un gasto muy parecido en los distintos estratos.

En el caso de los usuarios finales, los costos están asociados a los consumos durante el evento, como también a algunos implementos deportivos que compran. Ellos valoran de manera muy afectiva la asistencia a los eventos y los consideran como parte de la vida familiar. De forma consistente sugieren que los eventos faciliten muchas más comodidades a los asistentes, sobre todo a nivel de higiene y alimentación.

El caso de los usuarios finales de fútbol es particular. Analizando algunas de las variables que usualmente correlacionan con el estrato socioeconómico, se encuentra que los hinchas de Santafé poseen los niveles menores y los de La Equidad los mayores niveles. Sin embargo, el involucramiento emocional de los hinchas de Santafé y de Millonarios es mayor que el de los hinchas de La Equidad, esto a partir del perfil actitudinal. Es evidente que la edad en este caso correlaciona con el involucramiento, afirmando los estudios reseñados al inicio del documento, los cuales implican que a medida que aumenta la edad de las personas, su involucramiento emocional con el club deportivo es menor.

Los datos presentados en este artículo, permiten el desarrollo de diferentes aproximaciones de marketing a los consumidores de clubes deportivos, no solamente con el ánimo de fortalecer las organizaciones, sino como una forma de apoyar los programas sociales que pretenden fortalecer la práctica deportiva como una manera de mejorar la salud pública en nuestro país. 


\section{Bibliografía}

- Alfonzo, C.S. (2007) Siete marcas destinan más de 10\% de su presupuesto anual a la Copa América. Fuente: Sección Financiera, Periódico El Nacional, Miami, Julio 2, pg 1.

- Crissien, B., Sandoval, M. \& Cortes, O. (2008) Caracterización sectorial de las organizaciones deportivas de la ciudad de Bogotá. Universidad EAN.

- $\quad$ Duperly, J., Gámez, R., Lucumí, D., Venegas, A. \& Gómez L. (2005) 213 Nivel de actividad física global en la población adulta de Bogotá (Colombia). Prevalencia y factores asociados. Gaceta sanitaria: Órgano oficial de la Sociedad Española de Salud Pública y Administración Sanitaria, 19(3), 206-213.

- Fink, S., Trail, G. \& Anderson, D. (2002). An examination of team identification: Which motives are most salient to its existence? International Sports Journal, 6(2), 195-207.

- Fransi, E.C. (2004) Cómo comercializar las actividades deportivas. Madrid: Ediciones DeustoPlaneta de Agostini Profesional y Formación S.L.

- $\quad$ Funk ,D. \& James, J. (2004). The Fan Attitude Network (FAN) Model: Exploring Attitude Formation and Change among Sport Consumers. Sport Management Review, 7, 1-26.

- $\quad$ Funk, D. \& Pritchard, M. (2006). Sport publicity: Commitment's moderation of message effects. Journal of Business Research, 59, 913-621

- $\quad$ Funk ,D. , Ridinger, L. y Moorman , A. (2003). Understanding Consumer Support: Extending the Sport Interest Inventory (SII) to Examine Individual Differences among Women's Professional Sport Consumers. Sport Management Review, 6, 1-32.

- $\quad$ Lock, D., Darcy, S. \& Taylor, T. (2009). Starting with a clean slate: An analysis of member identification with a new sports team. Sport Management Review,12, 15-25.

- Mata, D. \& Garrido, J.P. (2006). Etnografía del deporte. Aproximación antropológica a través del modelo de los horizontes; deporte central vs. marginal. Madrid: Universidad Complutense de Madrid.

- $\quad$ Pedroza y Salvador (2003). El impacto del deporte en la economía: problemas de medición. Revista Asturiana de Economía, RAE 26.

- Sandoval, M. (1994). La psicología del consumidor: una discusión sobre su estado actual y aportes al mercadeo. Suma Psicológica, 1, 163-176.

- Smith, A. \& Stewart, B. (2009). The special features of sport: A critical revisit. Sport Management Review, en prensa.

- $\quad$ Wicker, P., Breuer, C. \& Pawlowski, T.(2009). Are sports club members big spenders? Findings from sport specific analyses in Germany. Sport Management Review, en prensa. 